\title{
EFFICACY AND SAFETY OF DULOXETINE IN THE TREATMENT OF CHEMOTHERAPY INDUCED PERIPHERAL NEUROPATHY: A SYSTEMATIC REVIEW AND META-ANALYSIS
}

\author{
I Putu Eka Widyadharma ${ }^{1}$, Chiquita Putri Vania Rau ${ }^{1}$, Rizaldy Taslim Pinzon ${ }^{2}$, Yudiyanta $^{3}$, Agung Wiwiek Indrayani ${ }^{4}$, \\ Thomas Eko Purwata ${ }^{1}$, Boya Nugraha ${ }^{5}$ \\ Correspondence: eka.widyadharma@unud.ac.id \\ ${ }^{l}$ Departement of Neurology, Faculty of Medicine, Udayana University and Sanglah General Hospital, Bali, Indonesia \\ ${ }^{2}$ Departement of Neurology, Faculty of Medicine, Duta Wacana University, Yogyakarta, Indonesia \\ ${ }^{3}$ Department of Neurology, Faculty of Medicine, Public Health, and Nursing, Gadjah Mada University, Yogyakarta, Indonesia \\ ${ }^{4}$ Department of Pharmacology, Faculty of Medicine, Udayana University, Bali, Indonesia \\ ${ }^{5}$ Department of Rehabilitation Medicine, Hannover Medical School, Germany
}

\section{Article History: \\ Received: October 5, 2019 \\ Accepted: December 1, 2020 \\ Published: January 1, 2021 \\ Cite this as: \\ Widyadharma IPE, , Rau CPV, Pinzon RT, Yudiyanta $Y$, Indrayani $A W$, Purwata TE Nugraha B. Efficacy and safety of duloxetine in the treatment of chemotherapy induced peripheral neuropathy: a systematic review and meta-analysis. Malang Neurology Journal; 2021.7:48- 55. \\ http://dx.doi.org/10.21776/ub.mnj .2021.007.01.10}

\section{ABSTRACT}

Background: One of the adverse effects of chemotherapy in the neurological field is chemotherapyinduced peripheral neuropathy (CIPN), it was an adverse effect caused by many chemotherapeutic regimens and a major cause of continuous pain in patients who survived cancer. When the symptoms get worse, survivor's quality of life is declining and they are often having problems with mental health, insomnia, cognitive functioning, fatigue, physical functioning, and pain. So far the choice of therapy for CIPN is still limited. Now, there was no drug approved to treat pain due to CIPN. Duloxetine are a SNRI (serotonin norepinephrine reuptake inhibitor), which it's useful in CIPN are highly supported by evidence.

Methods: We conducted a systemactic-computer based literature search on January 4, 2019 in PubMed database for article published between 2013 and 2018. We searched for a literature related with used a duloxetine for management of chemotherapy induced peripheral neuropathy.

Results: From the 4 studies that included in this review, the total participants are 478 patients with neuropathic pain and already get a chemotherapy regiment. From the meta-analysis showed one study had no effect, two studies had small effect, and one study had medium effect.

Conclusion: Duloxetine is a great option for the treatment of CIPN in especially reducing neuropathic pain.

Keywords: Pain. Neuropathic pain, chemotherapy induced peripheral neuropathy, cancer, duloxetine.

\section{Introduction}

With an estimated 32 million cancer survivors worldwide, it is increasingly important to understand the potential longlasting impacts of successful cancer treatments. One of the adverse effects of chemotherapy in the neurological field is chemotherapy-induced peripheral neuropathy (CIPN), it is an adverse effect caused by many chemotherapeutic regimens and a major cause of continuous pain in patients who survived cancer.

CIPN symptoms are the same as neuropathy in general. As described in a study in Indonesia, there are five clinical symptoms that are most dominant such as, electric shock like sensations, hyperalgesia, burning sensation, pinprick sensation, and paresthesia. ${ }^{2}$ The high success number of chemotherapy for the management of cancer also leads to an increase in the survival numbers of patients. However, also followed by the increasing numbers of patients who survived the cancer and suffers neuropathic pain.
Neuropathic pain is pain that arises due to damage from the path of the pain carrier itself, either in the form of impaired function or pathological changes in a nerve. ${ }^{3}$ Prevalence of CIPN varies depending on the type of chemotherapy, but in general is estimated about $68 \%$ in the short term and $30 \%$ in the long term, these development relate to either a single dose or accumulation dose. Chemotherapy agents that most often cause neurotoxic were taxanes and platins, which cause the CIPN on $30 \%-50 \%$ of patients who received the regimens. ${ }^{4}$ Infusion-related neuropathic symptoms also occur, particularly with oxaliplatin and paclitaxel regimens. ${ }^{5,6}$

When the symptoms get worse, survivor's quality of life was declining and they are often having problems with mental health, insomnia, cognitive functioning, fatigue, physical functioning, and pain. ${ }^{7,8} \mathrm{CIPN}$ also has effects in economic field, which caused CIPN leads to higher costs for healthcare. ${ }^{9}$ CIPN also effected on the chemotherapy dose reduction, changing, delays, or even cancelation, 
hence the pain caused by cancer treatment is a serious health issues.

Neuropathic pain in HIV (Human Immunodeficiency Virus), Chemotherapy Induced Peripheral Neuropathy and Lumbasacral Radiculopathy are often refractory to drugs and until now there are still no drugs that provide satisfactory results. ${ }^{10}$ Symptom management is the only action available for handling CIPN. So far the choice of therapy for CIPN is still limited. Now, there was no drug approved to treat pain due to CIPN. For the management of pain caused by cancer therapy, opioids is still the main choice, but less appropriate for chronic pain due to opioids owned a dependence effects. Meanwhile, a group of drugs that called adjuvant analgesic had been introduced for the treatment of chronic pain. Among these are topical agents, antidepressants (venlafaxine, duloxetine, TCA/tricyclic antidepressants), corticosteroids, N-methyl-D-aspartate antagonists, biphosphonates, cannabinoids, and also combination of antidepressants and anticonvulsants drugs (gabapentinoids, like pregabalin and gabapentin). ${ }^{11}$ Recently the use of antidepressants and anticonvulsants for CIPN has been increase because it brings the development of the positive results of the patients with fibromyalgia and diabetic neuropathy. ${ }^{12}$

Duloxetine is a SNRI (serotonin norepinephrine reuptake inhibitor), which very useful in CIPN and highly supported by evidence. ${ }^{13}$ Duloxetine acts by inhibiting norepinephrine and serotonin synaptic reuptake, make concentrations at the synapse increase then blocks input signals to the spinal dorsal horn neurons, and at the end make pain transmission decrease. Duloxetine also used and approved to reduce pain in patients with diabetic neuropathy. ${ }^{14}$

Several randomized control trials (RCT) had been done to see the effects of duloxetine CIPN. To our knowledge, there are still no systematic review had been done to summarize about these topic yet. So the author decided to assemble a systematic review to summarize this studies about safety and efficacy of duloxetine for management chemotherapyinduced peripheral neuropathy (CIPN) in particular for reducing the pain.

\section{Methods}

We conducted a systematic-computer based literature search on January 4, 2019 in PubMed database for article published between 2013 and 2018. We searched for a literature related with used a duloxetine for management of CIPN. We included the following terms as our strategy: (1) "neuropathy", "peripheral neuropathy", "neuropathic pain"; (2) "chemotherapy", "CIPN", "chemotherapyinduced"; (3) "pain", "painful”; (4) "management”, "therapy", "treatment"; (5) "duloxetine", "SNRI". Potentially relevant studies were also searched from a reference lists in retrieved articles and from Google Scholar.

Articles included for this review required to meet the following criteria: the study was carried out on humans adults (>18 years), patients had neuropathic pain due to chemotherapy, the article must be a research based study with a minimum level of evidence is level II, references using english, published in the last 5 years, and the outcome results included pain reduction and adverse effects (AE). The exclusion criteria are articles that did not provide new data, such as: review articles, case report, letters to the editor and editorials, and also book chapters.

Data were extracted from the published reports using a standard data collection. Characteristics of the article included: (1) patient demographics (sex, age, type of cancer), (2) study characteristics (type of study, study years, country), (3) intervention (comparator, dose of duloxetine, duration of the intervention), (4) outcomes (primary outcomes/pain reduction, with a standard deviation and adverse effects).

Analyses focused on change of the pain intensity on the patients and incidence also severity of the side effects of treatment. Number of patients who experience the adverse effects was results from asking and observing the patients for specific adverse events, like nausea and vomiting.

To obtain reliable conclusions, the included studies must be screened to find potential limitation and to minimize bias. In this review, we used a tool that provided by the Cochrane Collaboration for a risk of bias assessment. Cochrane Collaboration tool is based on several items such as incomplete outcome data, blinding outcome assessment, allocation concealment, and other bias. Based on the area, each study can be classified as unclear risk, low risk, and high risk. ${ }^{15}$

For the analysis and interpretation of the data of the studies selected, the mean value of the final pain and the effect size of each of the studies were calculated, as measurements of central tendency and dispersion. The standard deviation is the statistical element that takes into account both components, which allows to properly weights each study included in the meta-analysis; therefore, it was considered as inclusion criterion that each study had the mean value and the standard deviation for final pain both in the experimental group and in the placebo group.

Because of the variations of the tools that used in included studies, we used Hedge's g as a standarized measurement of the effect size. This measurement of the effect size does not depend on the standard deviations but based on the $g$ value in absolute value, like mention below ${ }^{16}$ :

- $0-0.2=$ no effect

- $0.2-0.5=$ small effect

- $0.5-0.8=$ medium effect

- $>0.8=$ large effect

\section{Results}

\section{Overview of The Included Trials}

The results of this strategy included identification of 181 articles from PubMed and 19 articles from other sources (eg. google scholar and reference lists), of which 18 were selected for retrieval. ${ }^{17-35}$ Therefore, 4 papers that used in this review already meet the inclusion criteria.17-20 All of the include studies published between 2013 and 2018. The selection process showed in Figure 1.

From the 4 studies that included in this review, the total participants are 478 patients with neuropathic pain and already get a chemotherapy regiment. ${ }^{17-20}$ 


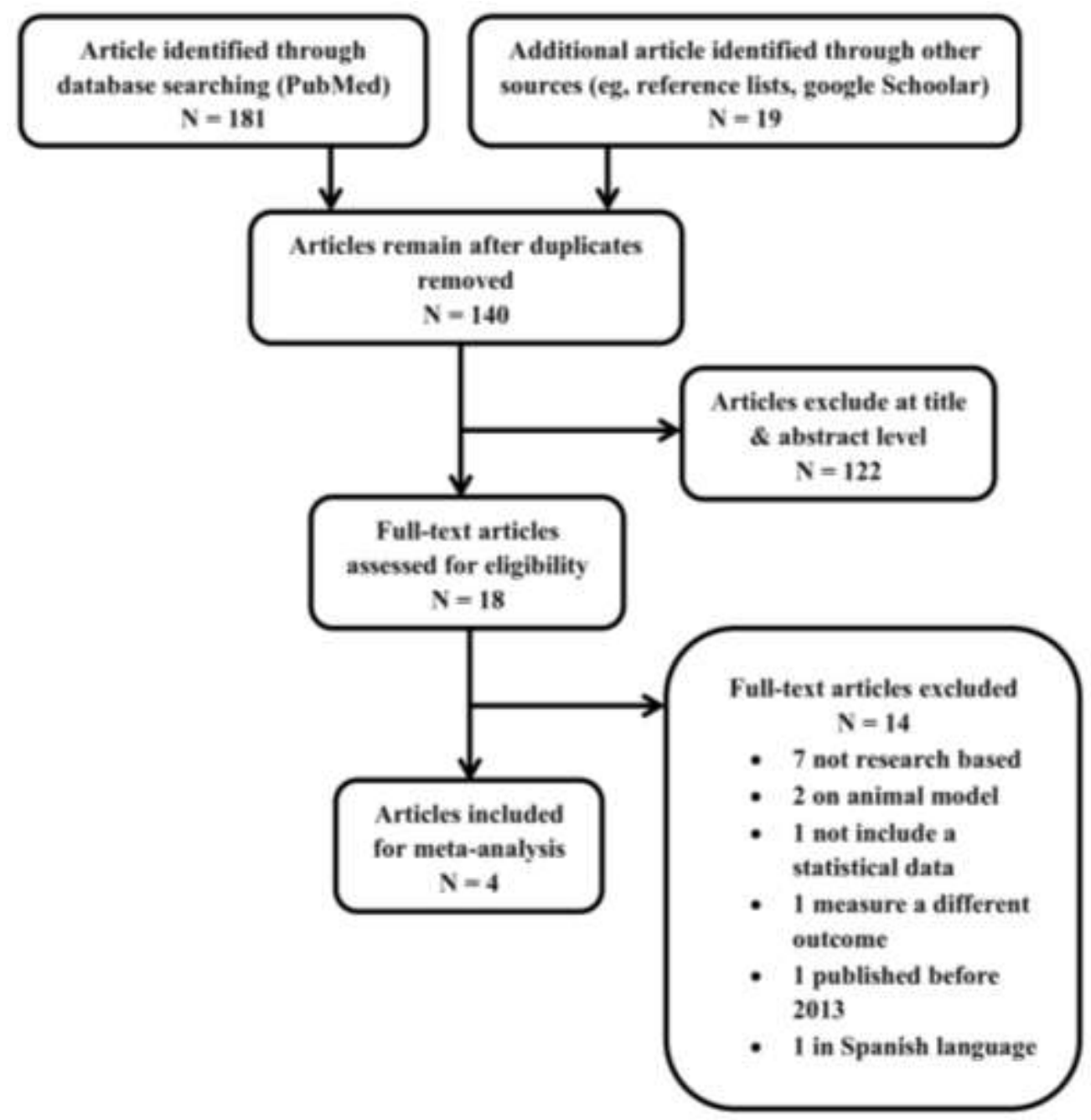

Figure 1. Selection process of the literature from PubMed database and additional sources which then through screening and eligibility process

Smith, et al 2013

Hirayama, et al 2015

Wang, et al 2017

Avan, et al 2018

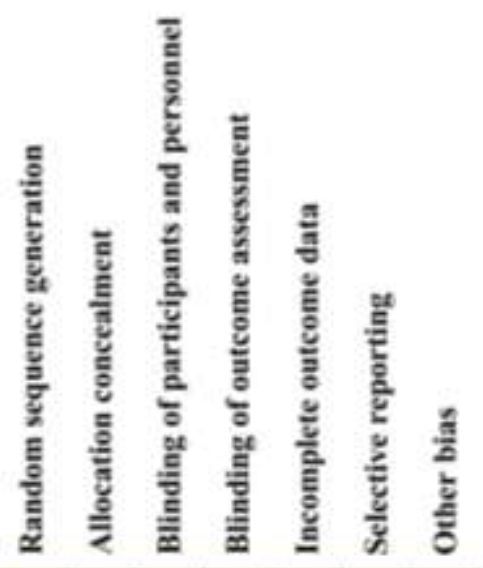

\begin{tabular}{|c|c|c|c|c|c|c|}
\hline+ & + & + & + & + & + & + \\
\hline+ & + & + & + & $?$ & - & + \\
\hline- & - & + & $?$ & + & + & + \\
\hline+ & + & + & + & + & + & + \\
\hline
\end{tabular}

+ Low risk of bias High risk of bias Unclear ris of Bias

Figure 2. Risk of bias 
Table 1 showed the demographic characteristics of these patients. Age of the included patients in this study ranged from 29 to 75 years. Two trials included patients with any type of cancer ${ }^{17,18}$ and other two with breast cancer. ${ }^{19,20}$

Accordingly, two trials used various agents17,18; one trials used paclitaxel20; and one trial used paclitaxel or docetaxel19. Study durations varied from 6 to 14 weeks. Dosage of the duloxetine in two studies were orally administered $30 \mathrm{mg}$ daily for 1 st week ${ }^{17,19}$ meanwhile in the other study $20 \mathrm{mg}$ daily for $1 \mathrm{st}$ week 18 . Continued with 30 $\mathrm{mg}$ twice daily19, $40 \mathrm{mg}$ daily 18 , and $60 \mathrm{mg}$ daily. ${ }^{17}$ Only one study that did not mention the duloxetine dose that used in study20. For the comparator, one trial used placebo17, one trial used pregabalin19, one trial compare with Vitamin B1218, and one trial used anti-neurotoxicity drugs20. All the studies ${ }^{17-20}$ assessed pain as one of the primary outcome, also included numbness, quality of life, emotional functioning, insomnia, etc. Primary outcome measures that included pain intensity in these study17-20 are: Visual Analog Scale (VAS), FACT-Tax Scales (Functional Assessment of Cancer Therapy-Taxane), BPI (Brief Pain Inventory) pain intensity, and EORTC QLQ-C30 (European Organization for the Research and Treatment of Cancer Quality of Life Questionnaire). All the study results that included in this review were then summarized in table 2.

\section{Risk of Bias and Meta-analysis Results}

For the risk of bias, according to Cochrane Collaborations, showed in figure 2. Two studies in this review showed "low risk" in all their area and the other two studies have several "high risk" item in the area "Random Sequence Generation", "Allocation concealment", and "Selective Reporting".

Regarding the statistical analysis using Hedge's g, one study showed no effect, which was Avan, et al comparing duloxetine and pregabalin [g: $-0.170,95 \%$ CI $(-0.604$; $0.264)]$. Two others studies showed a small effect which are Wang, et al [g: 0.204, 95\% CI $(-0.184 ; 0.595)]$ and Smith, et al [g: $0.422,95 \%$ CI $(0.156 ; 0.690)]$. The study by Hirayama et al showed medium effect [g: $0.603,95 \%$ CI ($0.076 ; 1.302)]$.

\section{Primary Outcomes}

The used of duloxetine for CIPN treatment has been done by Smith et al., ${ }^{17}$ to 231 cancer patients with certain criteria, but only 141 patients who finish this trial. This study claims as the first large phase 3 trial. The first phase of the trial results show that the average difference between the duloxetine group and placebo was $0.073(\mathrm{p}=0.003)$, better than the reference research ${ }^{36}$ using duloxetine for pain in diabetic neuropathy. Range for the difference in the average score of pain that FDA approved for diabetic neuropathy, fibromialgia, and osteoarthritis is $0.60-0.98$. But in contrast, this comparation still not right, because the mechanisms in peripheral neuropathy induced by chemotherapy which cause by taxane and platinum regiments, are difference from others nerve injury. However this study showed clinically important change, consider that patients experiencing an improvement in pain severity during initial treatment dominated by using of duloxetine. A decrease in pain score itself are over minimally significance threshold
(10\%) that set by IMMPACT (Initiative on Methods, Measurement, and Pain Assessment in Clinical Trials, which mission is to develop consensus reviews and recommendations for improving the design, execution, and interpretation of clinical trials of treatments for pain).

The results of Smith et al., ${ }^{17}$ confirmed by Hirayama et al.,18 which randomized 34 patients in Japan. Patients were divided into two groups: Group A who receive duloxetine followed by VB12 and Group B who receive VB12 followed by duloxetine. Group A received duloxetine 20 $\mathrm{mg}$ /day at first week continued with $40 \mathrm{mg} /$ day the next 3 weeks. Group B received VB12 $1.5 \mathrm{mg} /$ day for four weeks. Continued with the washout period 2-4 week, and then the treatment was exchange between 2 groups for another four weeks. They measure the pain and numbness every week using Visual Analog Scale. Obvious reductions seen in mean VAS score during the periods of duloxetine administration. These tended to decline 4 weeks after duloxetine administration. Duloxetine showed had significant differences for pain and numbness. Standard dosage of duloxetine in US and Japan are different based on duloxetine standard dosage for diabetic neuropathy (US higher than Japan).

Smith et al., study claimed to have a strengths on the design of the experiments that are randomized, prospective, using placebo control, and samples come from a wide geographical distribution. ${ }^{17}$ However, the study also acknowledged to have weakness, which are that implementing a scale measuring pain not specifically trained to assess the level of pain in CIPN patients and based only on CTCAE standard practical guidance. But since standard CTCAE consistent with academic and community clinical practice, then the findings that are based on this standard are declared valid. Another substantial limitation is the lack of enough times for duloxetine treatment, which the proper times are more than 5 weeks.

Hirayama et al., study have strength there are homogeneity at patients characteristics. ${ }^{18}$ This study said that no significant differences between groups in therapy types, median age, also ratio female and male. Limitation of these study are instead of using placebo as a comparator because ethical considerations, therefore using a VB12, that shown didn't have any effects on CIPN and only has a few side effects. But in the Hirayama study, shown some tendency for VB12 administration could improve numbness and pain, but the before and after difference are not significant.

Avan et al., examine the effectiveness of duloxetine in breast cancer patients who receive paclitaxel or docetaxel and experience TIPN (taxane-induced peripheral neuropathy) with age more than 18 , neuropathy grade $\geq 1$, and pain score $\geq 4$ based on VAS. ${ }^{19}$ The comparison between duloxetine and pregabalin with dosage $75 \mathrm{mg} /$ day pregabalin for first week, followed by $75 \mathrm{mg}$ twice a day for second until sixth weeks. Duloxetine given with dose 30 $\mathrm{mg}$ /day for first week, followed by $30 \mathrm{mg}$ twice a day for second until sixth weeks. In this case pregabalin showed more significant than duloxetine to reduce pain. The QOL score for both groups did not significanly difference. 
Table 1. Summary of study characteristic

\begin{tabular}{|c|c|c|c|c|c|c|c|c|c|c|}
\hline Study & Year & $\begin{array}{l}\text { Type of } \\
\text { Study }\end{array}$ & $\begin{array}{l}\text { Cancer } \\
\text { Type }\end{array}$ & $\begin{array}{l}\text { Chemotherapy } \\
\text { regimen }\end{array}$ & Country & $\begin{array}{l}\text { Sample } \\
\text { size }\end{array}$ & $\begin{array}{c}\text { Study } \\
\text { duration }\end{array}$ & Comparator & $\begin{array}{l}\text { Primary } \\
\text { outcome }\end{array}$ & $\begin{array}{c}\text { Adverse } \\
\text { Events as } \\
\text { Secondary } \\
\text { Outcome }\end{array}$ \\
\hline Smith, et al & 2013 & $\mathrm{RCT}$ & $\begin{array}{l}\text { Various } \\
\text { cancers }\end{array}$ & $\begin{array}{l}\text { Paclitaxel, } \\
\text { docetaxel, } \\
\text { cisplatin, } \\
\text { oxaliplatin }\end{array}$ & USA & 231 & 14 weeks & Placebo & $\begin{array}{l}\text { average pain } \\
\text { by BPI }\end{array}$ & Yes \\
\hline $\begin{array}{l}\text { Hirayama, et } \\
\text { al }\end{array}$ & 2015 & $\mathrm{RCT}$ & $\begin{array}{l}\text { Various } \\
\text { cancers }\end{array}$ & $\begin{array}{l}\text { paclitaxel, } \\
\text { oxaliplatin, } \\
\text { vincristine, } \\
\text { bortezomib }\end{array}$ & Japan & 34 & $\begin{array}{l}10-12 \\
\text { weeks }\end{array}$ & Vitamin B12 & $\begin{array}{l}\text { Change of } \\
\text { pain and } \\
\text { numbness } \\
\text { by VAS } \\
\text { score } \\
\end{array}$ & Yes \\
\hline Wang, et al & 2017 & $\begin{array}{l}\text { open label - } \\
\text { prospective }\end{array}$ & $\begin{array}{l}\text { Breast } \\
\text { cancer }\end{array}$ & Paclitaxel & Chinese & 131 & 12 weeks & $\begin{array}{c}\text { anti } \\
\text { neurotoxicity } \\
\text { drugs }\end{array}$ & $\begin{array}{l}\text { FACT-Tax } \\
\text { Scales }\end{array}$ & Yes \\
\hline Avan, et al & 2018 & RCT & $\begin{array}{l}\text { Breast } \\
\text { cancer }\end{array}$ & $\begin{array}{l}\text { paclitaxel or } \\
\text { docetaxel }\end{array}$ & Iran & 82 & 6 weeks & pregabalin & $\begin{array}{c}\text { QOL, pain } \\
\text { (EORTC } \\
\text { QLQ) }\end{array}$ & Yes \\
\hline
\end{tabular}

*RCT-Randomized Control Trials; BPI-Brief Pain Inventory; VAS-Visual Analogue Scale; FACT-Tax-Functional Assessment of Cancer Therapy-Taxane; QOL-Quality Of Life; EORTC-QLQ- European Organization for the Research and Treatment of Cancer Quality of Life Questionnaire

Table 2. Summary of study results

\begin{tabular}{|c|c|c|c|c|c|c|c|c|}
\hline Study & $\begin{array}{c}\text { Total } \\
\text { Participants } \\
\end{array}$ & $\begin{array}{l}\text { Age, } \\
\text { years }\end{array}$ & Sex, M/F & $\begin{array}{c}\text { Duloxetine } \\
\text { dosage }\end{array}$ & Comparator & Duration & Primary Outcome & $\begin{array}{c}\text { Secondary } \\
\text { Outcome }\end{array}$ \\
\hline $\begin{array}{l}\text { Smith, et al } \\
2013\end{array}$ & $\begin{array}{l}231 \text { total } \\
\text { Group A: } \\
109 \text {, } \\
\text { Duloxetine } \\
\text { first } \\
\text { Group B: } \\
\text { 111, placebo } \\
\text { first }\end{array}$ & $\begin{array}{l}30-75 \\
\mathrm{~A}=60 \\
(\text { mean) } \\
\mathrm{B}=59 \\
\text { (mean) }\end{array}$ & $\begin{array}{l}82 / 138 \\
A=38 / 71 \\
B=44 / 67\end{array}$ & $\begin{array}{l}\text { - } 30 \mathrm{mg} / \text { day }(1 \mathrm{st} \\
\text { week) } \\
\text { - } 60 \mathrm{mg} / \text { day } \\
\text { (next } 4 \text { weeks) }\end{array}$ & Placebo & $\begin{array}{l}\text { - Initial ( } 1-5 \\
\text { weeks) } \\
\text { - washout period } \\
\text { ( } 2 \text { weeks) } \\
\text { - cross over ( } 8-12 \\
\text { weeks) }\end{array}$ & $\begin{array}{l}\text { - Mean reducing } \\
\text { average pain, group } \\
\text { A } 1.06 \text { and group P } \\
0.34, \text { with p }=0.003 \\
\text { - RR (relative risk) } \\
\text { group A for } 30 \% \\
\text { pain decreasing = } \\
1.96,50 \% \text { pain } \\
\text { decreasing }=2.43\end{array}$ & $\begin{array}{l}\text { - Fatigue }(7 \%) \\
\text { - Nausea }(5 \%) \\
\text { - Insomnia }(5 \%)\end{array}$ \\
\hline $\begin{array}{l}\text { Hirayama, et } \\
\text { al } 2015\end{array}$ & $\begin{array}{l}34 \text { total } \\
\text { Group A : } \\
17, \\
\text { Duloxetine } \\
\rightarrow \text { Vitamin } \\
\text { B12 } \\
\text { Group B : } \\
\text { 17, Vitamin } \\
\text { B12 } \rightarrow \\
\text { Duloxetine }\end{array}$ & $\begin{array}{l}48-75 \\
A=61 \\
\text { (median) } \\
B=64 \\
\text { (median) }\end{array}$ & $\begin{array}{l}17 / 17 \\
A=8 / 9 \\
B=9 / 8\end{array}$ & $\begin{array}{l}\text { - } 20 \mathrm{mg} / \text { day }(1 \mathrm{st} \\
\text { week) } \\
\text { - } 40 \mathrm{mg} / \text { day } \\
\text { (next } 3 \text { weeks) }\end{array}$ & $\begin{array}{l}\text { Vitamin } \\
\text { B12 }\end{array}$ & $\begin{array}{l}\text { - } 4 \text { weeks } \\
\text { - washout period } \\
\text { (2-4 weeks) } \\
\text { - cross over (4 } \\
\text { weeks) }\end{array}$ & $\begin{array}{l}\text { Hazard ratios } \\
\text { duloxetine groups } \\
\text { in initial treatment: } \\
\text { - A } 30 \% \\
\text { decreasing in pain } \\
\text { were } 0.40 \text { and } \\
\text { numbness } \\
\text { duloxetine were } \\
0.25 \\
\text { - A } 50 \% \\
\text { decreasing were } \\
0.28 \text { and } 0.25 \text {, } \\
\text { respectively }\end{array}$ & $\begin{array}{l}\text { - Fatigue (17.6 } \\
\%) \text {. } \\
\text { - Insomnia } \\
\text { - Somnolence } \\
\text { - Nausea }\end{array}$ \\
\hline $\begin{array}{l}\text { Wang, et al } \\
2017\end{array}$ & $\begin{array}{l}102 \text { total } \\
\text { Group A : } \\
53 \text {, } \\
\text { duloxetine } \\
\text { Group B : } \\
\text { 49, control }\end{array}$ & $\begin{array}{l}A=49 \\
(43-53) \\
B=51 \\
(43-57)\end{array}$ & - & - & $\begin{array}{l}\text { Anti- } \\
\text { neurotoxicity } \\
\text { drugs (NSAID, } \\
\text { fish oil, Vit B) }\end{array}$ & 12 weeks & $\begin{array}{l}\text { The mean } \\
\text { reducing pain } \\
\text { score in duloxetine } \\
\text { groups versus } \\
\text { other-anti } \\
\text { neurotoxicity drug } \\
\text { groups are } 3.89 \\
\text { and } 2.10 \text {. }\end{array}$ & $\begin{array}{l}\text { - Eye distention } \\
\text { - Somnolence } \\
\text { - Nausea } \\
\text { - Dizziness } \\
\text { - Constipation }\end{array}$ \\
\hline $\begin{array}{l}\text { Avan, et al } \\
2018\end{array}$ & $\begin{array}{l}82 \text { total } \\
\text { Group A : } \\
40, \\
\text { Pregabalin } \\
\text { Group B : } \\
42, \\
\text { Duloxetine }\end{array}$ & $\begin{array}{l}29-72 \\
A=29-72 \\
B=30-71\end{array}$ & - & $\begin{array}{l}\text { - } 30 \mathrm{mg} / \mathrm{day} \text { (1st } \\
\text { week) } \\
\text { - } 30 \mathrm{mg} \text { twice a } \\
\text { day (until } 6 \\
\text { week) }\end{array}$ & pregabalin & 6-weeks & $\begin{array}{l}\text { The mean score of } \\
\text { pain significantly } \\
\text { declined both in } \\
\text { pregabalin and } \\
\text { duloxetine group } \\
(p<0.001)\end{array}$ & $\begin{array}{l}\text { Nausea \& } \\
\text { vomiting }\end{array}$ \\
\hline
\end{tabular}

*NSAID-Non Steroidal Anti-Inflammatory Drugs 


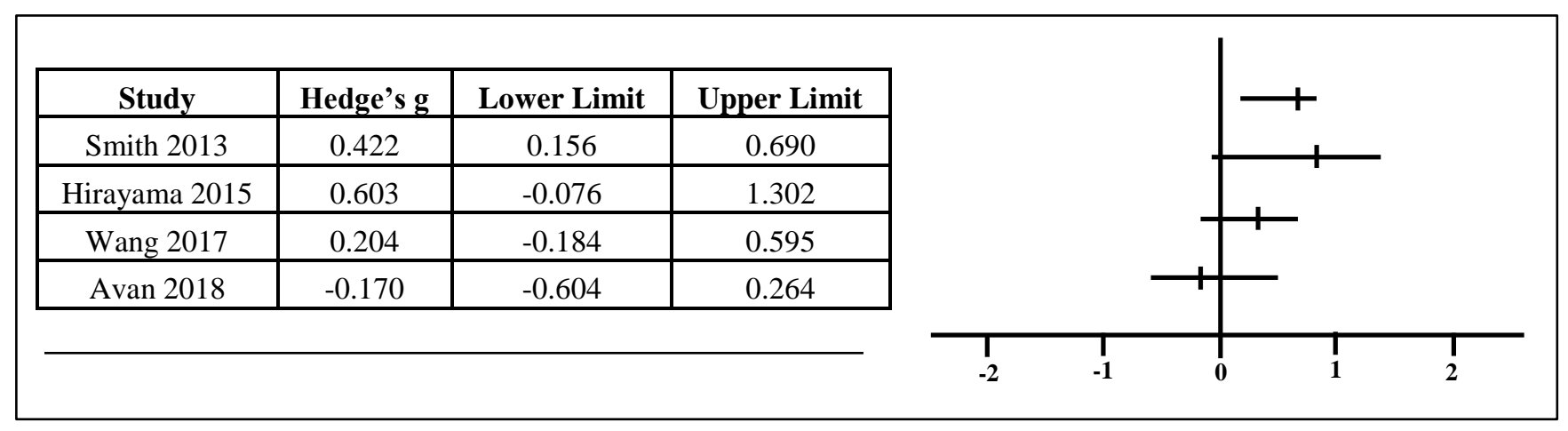

Figure 3. Forest plot

Same trials recently in China, with 102 breast cancer patient, median age is 50 years (range 25-60 years). ${ }^{20}$ In these trial, duloxetine given orally $30 \mathrm{mg}$ /day for the first 4 weeks and $60 \mathrm{mg} /$ day for the next 8 weeks. The comparison is other neurotoxicity drugs with the same duration. Duloxetine shows a better results for reducing pain seen in FACT-Tax with median decrease is $4(2-6)$ and the other drugs is $1(0-4)$ with $\mathrm{p}=0.005$.

\section{Secondary Outcomes (Adverse Effects)}

Several things to note from the use of duloxetine related adverse effects is duloxetine could not be used in conjunction with medications are serotonin reuptake inhibitors for the process because there are an increasing risk of the ocurence of the syndrome serotonin. ${ }^{39}$ Duloxetine also couldn't administrate together with substrate CYP P450 2D6 because duloxetine is a moderate inhibitor of the enzyme. It could lead to an increase in the concentration of serum drug substrate and related to toxicity. ${ }^{40-43}$ The use of duloxetine with NSAID, warfarin, or both, might increase the risk of bleeding. ${ }^{39,44}$ Duloxetine also inhibits the conversion of tamoxifen to endoxifen, active metabolits, related properties of an inhibitor CYP P450 2D6. ${ }^{39,41,45,46}$

All the adverse effects are summarized in table 3. Study in Japan showed that fatigue happen in $17,6 \%$ patients $(6 / 34)$, and the others are nausea $(3 \%)$, somnolence $(2 \%)$, and insomnia (2\%).18 Approved by Smith et al, that fatigue, insomnia, and nausea were the most common adverse effects happened, with presentase $7 \%, 5 \%$, and $5 \%$ respectively. ${ }^{17}$ Avan et al also confirmed nausea and vomiting was more common in patients that use duloxetine, different with pregabalin patients that more complain about somnolence and dizziness. ${ }^{19}$ The other adverse effects added by Wang et al., such as constipation, dizziness, and eye distention. ${ }^{20}$

Table 3. Sumarry of adverse effects

\begin{tabular}{l}
\hline Adverse Effects \\
\hline Fatigue \\
Somnolence \\
Dizziness/Giddiness \\
Nausea vomiting \\
Constipation \\
Headache \\
Eye Distention \\
Dysgeusia \\
\hline
\end{tabular}

\section{Discussion}

Duloxetine is widely used and proved for the management of diabetic neuropathy (pain that caused by damage of the nerve in patients with diabetes). ${ }^{16}$ The newest guideline about prevention and treatment of adult patients with cancer from ASCO (American Society of Clinical Oncology) also recommends the use of duloxetine for management of CIPN.15 The purpose of this study is to systematically review and determine the efficacy and safety of using duloxetine for management CIPN in particular for reducing the pain.

There are still a few direct evidence to support using drugs from adjuvant analgesics groups (e.g., antidepressants and anticonvulsants) in the CIPN setting, although many clinicians empirically use them based on other pain management principles. ${ }^{35}$ The author of this article found 4 experimental study that assess the effects of using duloxetine for CIPN, but these 4 study has different tools to measure the outcome which include pain as one of them ${ }^{.17-}$

${ }^{20}$ Nowdays, there is no consensus exists regarding which of these measures are the best for assessing the outcomes of CIPN treatment. This lack of standardized primary outcome measurements necessitates further studies that characterize and separate CIPN-related pain from other sensory symptoms; using standard outcome measures will help to determine the best outcome measure for future CIPN treatment trials.

There are some previous positive trials of using duloxetine for decreasing pain scores in the treatment of neuropathic pain resulting from chemotherapy agent. Smith and colleagues (2013) concluded that compared to placebo, using duloxetine for five weeks showed a clinically and statistically pain improvement. ${ }^{17}$ After four weeks treatment of duloxetine shown a lower mean Visual Analog Scale (VAS), compared to the one who get Vitamin B12 for treatment.18 The meaningful reduce from the mean Visual Analog Scale (VAS) scores shown during the duloxetine treatment in Japan patients.18 Using duloxetine for decreasing a pain intensity also seen in open label prospective experiment to breast cancer patients in China. ${ }^{20}$ This study shown a better pain intensity after get duloxetine for 12 weeks, proven by Functional Assessment of Cancer Therapy-Taxane (FACT-Tax) pain decrease 4 in duloxetine group and 1 in control group. Other studies also observed significant improvement in emotional functioning, pain, global health, and QOL domains of EORTC QLQ C-30 questionnaire in duloxetine group. Duloxetine was 
successfully used for patients with cancer who have mood disorder, and it was associated with improvement in global QOL, especially in emotional functioning, pain, global health, and QOL subscales. ${ }^{19}$

From the meta-analysis results we could see that in the forest plot (figure 3), study by Avan, et al had a tendency to stay away from duloxetine, which is probably because the study conducted by Avan used pregabalin as a comparison instead of placebo. As we know, pregabalin showed more effectiveness than duloxetine to treat peripheral neuropathy. Meanwhile the opposite from Avan, the only study that supports duloxetine completely is study by Smith, et al. Seen by the line that represent Smith on the forest plot, the line does not touch the line 0. This is because Smith, et al study was the only study in this review which used placebo as a comparison.

The increase in the number of occurrence of adverse events is an issue that should be resolved when adding a drug to treat a chemotherapy-induced peripheral neuropathy. Therefore, it is important to report adverse events as secondary outcomes when evaluating the efficacy and safety of the use of duloxetine for CIPN. Adverse effects of duloxetine were very well tolerated in a population of patients with breast cancer in China. ${ }^{20}$ The adverse effects were found are somnolence, constipation, dizzined, eye distention, and nausea. According to Wang et al., to decrease the possibility to have nausea and vomiting, patients should swallowing duloxetine (capsule form) after meals also without chewing and crushing. ${ }^{20}$ These are consistent with Avan et al., that the adverse effects were mild and well-tolerated. ${ }^{19}$ In the study by Smith et al., patients who discontinued because of the adverse effects are higher on groups that are used duloxetine as their first treatment compared to the placebo groups $(11 \%$ versus $1 \%) .{ }^{17}$ Beside that, Smith also reported the other adverse effects that are nausea, insomnia and fatigue. Same with Smith, in the study by Hirayama five patients was discontinued because of fatigue.18 Fatigue was the most frequent adverse effects according to Hirayama, seen in $6 / 34$ patients $(17.6 \%)$

\section{Conclusion}

There are some limitations about this study, one of them was the included study in this review was only 4 , due to lack of RCT in this population. Resulting there is still not enough evidence to evaluate the effects of duloxetine for the management of CIPN. Randomized Control Trials which include a large number of participant was needed in the future. We could conclude that for the treatment of CIPN, duloxetine is a great option, especially for reducing neuropathic pain. But in comparison with pregabalin showed less effective. The adverse effects of duloxetine a majority are mild and well-tolerated, but clinicians need to pay attention when give duloxetine to elderly people, maybe an adjusting dose should be considered.

\section{Acknowledgement}

None

\section{Conflict of Interest}

All authors have no conflicts of interest to report. All of the authors of the manuscript did not receive any remuneration.

\section{References}

1. Farguhar-Smith P, Brown MRD. Persistent pain in cancer survivors: Pathogenesis and treatment options. Pain Clinical Updates XXIV (London, UK); 2016. 18

2. Purwata TE, Sadeli HA, Yudiyanta, Widyadharma IP, Anwar Y, et al. Characteristics of neuropathic pain in Indonesia: A hospital based national clinical survey. Purwata TE, Sadeli HA, Yudiyanta, Widyadharma IP, Anwar Y, et al. Characteristics of neuropathic pain in Indonesia: A hospital based national clinical survey. Neurology Asia 2015; 20(4) : 389 - 394. Available from : : https://www.neurologyasia.org/articles/neuroasia-2015-20(4)-389.pdf

3. Widyadharma, IP. Pain Education: Nyeri Polineuropati Diabetik. Pustaka Bangsa Press. 2017. 101-109.

4. Argyriou AA, Bruna J, Marmiroli P, Cavaletti G. Chemotherapy-induced peripheral neurotoxicity (CIPN): an update. Crit Rev Oncol Hematol; 2012. 82(1):51-77. DOI: 10.1016/j.critrevonc.2011.04.012.

5. Reeves BN, Dakhil SR, Sloan JA, Wolf SL, Burger KN, Kamal A, et al. Further data supporting that paclitaxel-associated acute pain syndrome is associated with development of peripheral neuropathy: North Central Cancer Treatment Group trial N08C1. Cancer; 2012. 118(20):5171-5178.

DOI: $10.1002 /$ cncr.27489

6. Argyriou AA, Cavaletti G, Briani C, Velasco R, Bruna $\mathrm{J}$, Campagnolo $\mathrm{M}$, et al. Clinical pattern and associations of oxaliplatin acute neurotoxicity. Cancer; 2012. 119(2):438-444.

DOI: $10.1002 / \mathrm{cncr} .27732$

7. Bao T, Basal C, Seluzicki C, Li SQ, Seidman AD, Mao JJ. Long-term chemotherapy-induced peripheral neuropathy among breast cancer survivors: prevalence, risk factors, and fall risk. Breast Cancer Res Treat; 2016. 159(2):327-33.

DOI: $10.1007 / \mathrm{s} 10549-016-3939-0$.

8. Kolb NA, Smith AG, Singleton JR, Beck SL, Stoddard GJ, Brown S, et al. The Association of Chemotherapy-Induced Peripheral Neuropathy Symptoms and the Risk of Falling. JAMA Neuro; 2016. 73(7):860-6

DOI: 10.1001/jamaneurol.2016.0383.

9. Pike CT, Birnbaum HG, Muehlenbein CE, Pohl GM, Natale RB. Healthcare costs and workloss burden of patients with chemotherapy-associated peripheral neuropathy in breast, ovarian, head and neck, and nonsmall cell lung cancer. Chemother Res Pract; 2012. 913848. DOI: 10.1155/2012/913848

10. Purwata TE, Widyadharma IP. Pregabalin as the Cornerstone of Treating Neuropathic Pain. PKB XXIII. 2015. 9-21

11. Esin E, Yalcin S. Neuropathic cancer pain: What we are dealing with? How to manage it? OncoTargets and therapy; 2014. 7: 599-618.

DOI: $10.2147 /$ OTT.S60995 
12. Wiffen PJ, Derry S, Moore RA, Aldington D, Cole P, Rice AS, et al. Antiepileptic drugs for neuropathic pain and fibromyalgia - an overview of Cochrane reviews. Cochrane Database Syst Rev; 2013. 11:CD010567. DOI: 10.1002/14651858.CD010567.pub2

13. Hershman DL, Lacchetti C, Dworkin RH, Lavoie Smith EM, Bleeker J, Cavaletti G, et al. Prevention and management of chemotherapy-induced peripheral neuropathy in survivors of adult cancers: American Society of Clinical Oncology clinical practice guideline. Journal of clinical oncology: official journal of the American Society of Clinical Oncology; 2014. 32: 1941-1967. DOI: 10.1200/JCO.2013.54.0914

14. Aziz MT, Good BL, Lowe DK. Serotoninnorepinephrine reuptake inhibitors for the management of chemotherapy-induced peripheral neuropathy. The Annals of pharmacotherapy; 2014. 48:626-632. DOI: 10.1177/1060028014525033

15. Higgins JP, Green S. Cochrane handbook for systematic reviews of interventions version 5.1.0 [updated March 2011] [database on the internet]. London, The Cochrane Collaboration. 2011 [cited 2019 March 9]. Available from http://handbook-5-1. cochrane.org/

16. Denis DJ. Understanding Cohen's d [database on the internet]. QUANT. 2012. [cited 2019 March 9]. Available from:

http://www.statpt.com/applied_gen/cohen_d.pdf

17. Smith EML, Pang H, Cirrincione C, Fleishman S, Paskett ED, Ahles T, et al. Effect of duloxetine on pain, function, and quality of life among patients with chemotherapy-induced painful peripheral neuropathy: a randomized clinical trial. JAMA; 2013. 309:13591367. DOI: 10.1001/jama.2013.2813

18. Hirayama Y, Ishitani K, Sato Y, Iyama S, Takada K, Murase K, et al. Effect of duloxetine in Japanese patients with chemotherapy-induced peripheral neuropathy: a pilot randomized trial. International journal of clinical oncology; 2015. 20(5):866-71. DOI: 10.1007/s10147-015-0810-y

19. Avan R, Janbabaei G, Hendouei N, Alipour A, Borhani S, Tabrizi N, et al. The effect of pregabalin and duloxetine treatment on quality of life of breast cancer patients with taxane-induced sensory neuropathy: A randomized clinical trial. Journal of Research in Medical Sciences; 2018. 23:52.

DOI: 10.4103/jrms.JRMS_1068_17.

20. Wang J, Li Q, Xu B, Žhang T, Chen S, Luo Y. Efficacy and safety of duloxetine in Chinese breast cancer patients with paclitaxel-induced peripheral neuropathy. Chin J Cancer Res; 2017. 29(5):411-418. DOI: $10.21147 /$ j.issn.1000-9604.2017.05.05

21. Smith EML, Pang H, Ye C, Cirrincione C, Fleishman S, Paskett ED, et al. Predictors of duloxetine response in patients with oxaliplatin-induced painful chemotherapy-induced peripheral neuropathy (CIPN): A secondary analysis of randomised controlled trial CALGB/alliance 170601. European Journal of Cancer Care; 2017. 26(2):e12421. DOI: 10.1111/ecc.12421

22. Farshchian N, Alavi A, Heydarheydari S, Moradian N. Comparative study of the effects of venlafaxine and duloxetine on chemotherapy-induced peripheral neuropathy. Cancer Chemotherapy and Pharmacology; 2018. 82(5):787-793.

DOI: $10.1007 / \mathrm{s} 00280-018-3664-\mathrm{y}$.

23. Otake K, Yoshino K, Ueda Y, Sawada K, Mabuchi S, Kimura $\mathrm{T}$, et al. Usefulness of Duloxetine for Paclitaxel-Induced Peripheral Neuropathy Treatment in Gynecological Cancer Patients. Anticancer Research; 2015. 35: 359-364. Available from : http://ar.iiarjournals.org/content/35/1/359.full.pdf+htm 1

24. Yang YH, Lin JK, Chen WS, Lin TC, Yang SH, Jiang $\mathrm{JK}$, et al. Duloxetine improves oxaliplatin-induced neuropathy in patients with colorectal cancer: an open-label pilot study. Support Care Cancer; 2012. 20:1491-1497. DOI: 10.1007/s00520-011-1237-2

25. Kanbayashi $Y$, Inagaki $M$, Ueno $H$, Hosokawa $T$. Predictors of the usefulness of duloxetine for chemotherapy- induced peripheral neuropathy. Med Oncol; 2017. 34:137. DOI: 10.1007/s12032-0170995-1

26. Matsuoka H, Ishiki $H$, Iwase $S$, Koyama A, Kawaguchi T, Kizawa Y, et al. Study protocol for a multi-institutional, randomised, double-blinded, placebo-controlled phase III trial investigating additive efficacy of duloxetine for neuropathic cancer pain refractory to opioids and gabapentinoids: the DIRECT study. BMJ Open; 2017. 7:e017280.

DOI: 10.1136/bmjopen-2017-017280

27. Okuma K, Shiraishi K, Kanai Y, Nakagawa K. Improvement in quality of life by using duloxetine for chemotherapy-induced peripheral neuropathy (CIPN): a case report. Support Care Cancer; 2016. 24:4483-4485. DOI: 10.1007/s00520-016-3349-1

28. Pachman DR, Watson JC, Lustberg MB, D Nina, Johnston W, A Chan, et al. Management options for established chemotherapy-induced peripheral neuropathy. Support Care Cancer; 2014. 22(8):228195. DOI: 10.1007/s00520-014-2289-x.

29. Kane CM, Mulvey MR, Wright S, Craigs C, Wright JM, Bennett MI. Opioids combined with antidepressants or antiepileptic drugs for cancer pain: Systematic review and meta-analysis. Palliat Med; 2018. 32(1):276-286. DOI: $10.1177 / 0269216317711826$.

30. Jongen JLM, L Mark, Huijsman, Jessurun J, Ogenio K, Schipper D, et al. The Evidence for Pharmacologic Treatment of Neuropathic Cancer Pain: Beneficial and Adverse Effects. Journal of Pain and Symptom Management; 2013. 46(4):581-590.e1.

DOI: $10.1016 /$ j.jpainsymman.2012.10.230

31. Kim W, Chung Y, Choi S, Min B, Kim SK. Duloxetine Protects against Oxaliplatin-Induced Neuropathic Pain and Spinal Neuron Hyperexcitability in Rodents. Int. J. Mol. Sci; 2017. 18, 2626. DOI: 10.3390/ijms18122626

32. Hopkins HL, Duggett NA, Flatters SJL. Chemotherapy-induced painful neuropathy: pain-like behaviours in rodent models and their response to commonly-used analgesics. Curr Opin Support Palliat Care; 2016. 10(2):119-128.

DOI: $10.1097 /$ SPC.0000000000000204 